\title{
RELAÇŌES DE TROCA COM EFEITO TECNOLÓGICO NO MERCADO DOMÉSTICO DE ARROZ, MILHO, CAFÉ E SOJA ${ }^{1}$
}

\author{
Niraldo José Ponciano ${ }^{2}$ \\ Paulo Marcelo de Souza ${ }^{3}$ \\ Henrique Tomé da Costa Mata \\ Edenio Detmann 5
}

\begin{abstract}
Resumo - O objetivo deste trabalho foi avaliar, por meio da relação de troca, o comportamento da rentabilidade de duas culturas voltadas para o mercado interno e de duas culturas de exportação. Outro objetivo foi identificar a compensação do acréscimo de produtividade na queda de preços. Foram estimadas as taxas geométricas de crescimento da produção, da área e da produtividade. Os termos de troca foram estimados pela relação entre os índices de preço dos insumos e os índices de preços obtidos pelo agricultor na comercialização de seu produto. Os resultados mostraram forte tendência de deterioração dos termos de troca para todos os produtos analisados. Constatou-se que esses efeitos foram mais acentuados para arroz e milho. Tal comportamento associase ao fato de as culturas de arroz e de milho serem destinadas ao mercado interno, e suas demandas têm sido mais inelásticas em relação às culturas de soja e de café.
\end{abstract}

Palavras -chave: termos de troca, grãos, insumos, preços, produtividade, renda.

\section{Introdução}

A determinação do comportamento do mercado doméstico de grãos envolve estudos que avaliam, conjuntamente, a produção, a produtividade e os preços. Contudo, em razão de a rentabilidade do produtor agrícola ser fortemente influenciada por outros fatores alheios, a avaliação da relação de troca considerando o efeito tecnológico torna-se alvo principal de estudos em que se busca determinar o comportamento da rentabilidade.

Recebido em: 1\%/12/2006 Aceito em: 16/04/2007

Professor da Universidade Federal do Norte Fluminense. E-mail: ponciano@uenf.br

Professor da Universidade Federal do Norte Fluminense. E-mail: pmsouza@uenf.br

4 Professor da Universidade Federal da Bahia. E-mail: hnrmata@hotmail.com

5 Professor da Universidade Federal de Viçosa. E-mail: detmann@ufv.br 
Segundo Nakano (1981), o produtor é dinâmico do ponto de vista do processo técnico, mas sua estrutura de organização contribui para o processo contínuo de deterioração nos termos de troca. A relação é cada vez mais desfavorável para o agricultor que se relaciona com o complexo agroindustrial, constituído de empresas oligopolistas organizadas, que fornecem insumos e máquinas agrícolas, de um lado, e compram e processam produtos agrícolas, de outro.

A variabilidade da produção e dos preços agrícolas brasileiros, nas últimas décadas, resultou na instabilidade da renda do produtor rural. Para KamChings e Teixeira (1995), as intervenções do governo no mercado agrícola sacrificaram a produção de alimentos no País. Esses mesmos autores, citando Lopes (1992), atribuem às intervenções a transferência anual de renda da agricultura, entre 1960 e 1992, de aproximadamente 40\% do PIB agrícola. Assim, o setor ficou comprometido em termos de formação de capital, de competitividade e de manutenção de sua renda em relação aos setores não-agrícolas.

Guiado pela luz da hipótese de que os produtos exportáveis recebem sinais do mercado internacional e que o mesmo não acontece com os produtos do mercado doméstico, é importante separar os produtos agrícolas por destino de mercado para analisar comparativamente a instabilidade de preços nos dois mercados. Assim, pode-se avaliar o comportamento dos preços e os efeitos da política de abertura comercial para os produtos comercializados internamente e para os exportáveis.

O avanço tecnológico agrícola tem sido evidenciado por meio da adoção de variedades melhoradas geneticamente, mecanização agrícola, fertilizantes, defensivos, plantio direto, entre outros. Essas inovações tecnológicas tendem a aumentar o produto físico marginal e o produto físico médio e, por outro lado, reduzem o custo marginal e o custo variável médio. Além da tecnologia, as condições climáticas e os preços dos insumos são fatores relevantes na oferta de produtos agrícolas. Quando se elevam os preços de insumos, isso acarreta aumento nos custos marginal e médio, tudo o mais permanecendo constante, e a relação de troca piora para o produtor. 


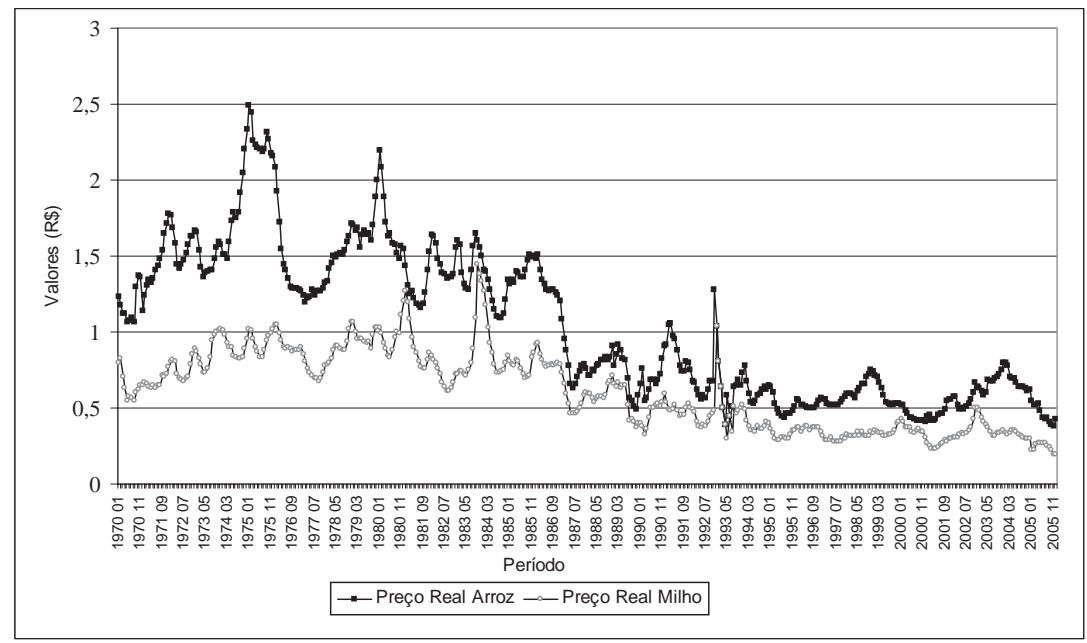

Figura 1 - Comportamento dos preços das culturas domésticas (arroz e milho) no período de 1970 a 2005, em $\mathrm{R} \$ / \mathrm{kg}$ (base dez. 2005)

Observa-se na Figura 1 que ao longo dos anos houve redução nos preços de arroz e de milho. O preço recebido pelo produtor apresenta grande oscilação, decorrente das variações na oferta. Embora o consumo seja relativamente constante, a produção apresenta sazonalidade em função de expectativa de preços e de fatores climáticos. Esse tipo de produto tende a apresentar elasticidade-renda da demanda negativa; isso indica que, à medida que a renda da população cresce, a demanda diminui e o produto passa a ser substituído por produtos mais nobres, como, por exemplo, carnes (Hoffman, 1994). 


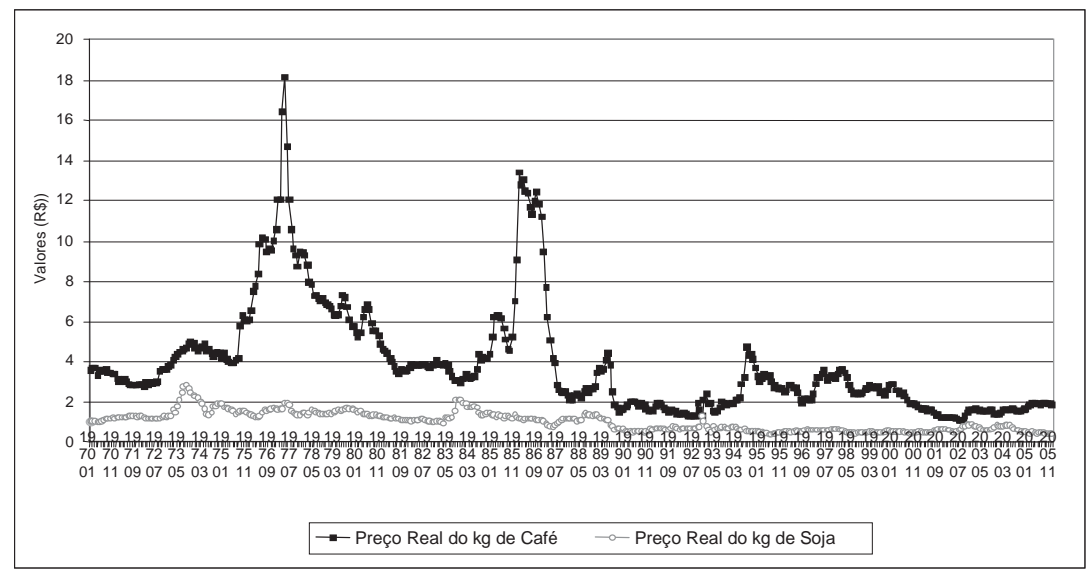

Figura 2 - Comportamento dos preços das culturas de exportação (café e soja) no período de 1970 a 2005 , em $\mathrm{R} \$ / \mathrm{kg}$ (base dez. 2005)

Na Figura 2, também se constatam reduções nos preços reais das culturas de exportações (café e soja); o mercado internacional dessas commodities influencia seus preços, assim como as políticas comerciais e cambiais vigentes. $\mathrm{O}$ preço recebido pelo produtor de café foi mais oscilante em decorrência das variações na oferta mundial. Destacam-se dois picos elevados de preços nos anos de 1975/76 e de 1985/86, afetados por vários fatores, dentre os quais o clima adverso, que reduziu a produção de café no Brasil. Tanto Bacha (1998) quanto Delfin Neto (1981) afirmam que a cafeicultura brasileira apresenta pelo menos dois tipos de ciclo dos preços: ciclo plurianual, pelo fato de a cultura do cafeeiro apresentar valores distintos de preços e produção ao longo dos anos; e ciclo bienal, decorrente de adversidades climáticas e fisiológicas do cafeeiro, o que proporciona grandes flutuações do volume produzido de um ano para o outro. Por outro lado, o comportamento dos preços da soja apresentou relativa estabilidade decrescente, o que pode estar ligado ao fato de ser uma commodity que sofre acirramento da competição no mercado internacional e facilmente ajustável devido ao ciclo curto de produção. 
A queda nos preços dos produtos agrícolas influencia mais a renda dos produtores brasileiros do que o crescimento da produtividade? Quais condições exercem mais influência no comportamento da renda de produtos comercializados em mercado doméstico e em mercado de exportação? A renda dos produtores depende tanto do preço relativo como da produtividade. Na situação em que tanto o preço relativo quanto a produtividade são favoráveis, a renda dos produtores aumentará; caso contrário, reduzirá.

Sob certo aspecto, pode-se enunciar como proposição que as inovações tecnológicas indutoras da expansão da produtividade agrícola brasileira tiveram papel preponderante nas últimas décadas, porém foram insuficientes para compensar o viés do efeito desfavorável nos preços relativos entre insumo e grãos. Dessa forma, supõe-se, provisoriamente, que no longo prazo a relação de troca foi desfavorável para o produtor brasileiro, visto que o efeito preço relativo sobrepõe-se ao efeito produtividade; isso nada mais é do que modernização com empobrecimento do agricultor.

O efeito dos preços pagos pelos insumos sobre os preços recebidos pelo produto agrícola pode ser pensado no contexto da interação da demanda e da oferta nos mercados agrícolas. A alteração do preço pago pelo insumo desloca a curva de oferta do produto agrícola. Quanto mais inelástica for a curva de demanda por esse produto, maior será o impacto sobre o seu preço de equilíbrio. Nesse sentido, supõe-se que os efeitos dos preços pagos sobre os preços recebidos tenham sido mais acentuados nos produtos domésticos. Na mesma linha de raciocínio, acredita-se que, após a abertura da economia (início da década de 1990), as demandas pelos produtos agrícolas se tornaram mais elásticas em relação ao período anterior. Dessa forma, supõe-se que a partir da abertura econômica a relação de troca tende a se tornar mais estável e mais favorável ao produtor rural.

Objetivou-se avaliar, por meio da relação de troca, o comportamento da rentabilidade da produção de arroz, milho, café e soja, no Brasil, bem 
como identificar o efeito tecnológico na compensação da queda de preços, em um horizonte de longo prazo.

O artigo está organizado em três seções, além desta introdução. A segunda seção trata dos aspectos metodológicos. Inicia-se com os procedimentos de obtenção dos indicadores de crescimento e de modernização mediante taxas geométricas de crescimento e, em seguida, apresenta-se o processo de obtenção da relação de troca e a fonte dos dados. Na terceira seção são apresentados os resultados, por meio de ilustrações gráficas e discussão destes. Finalmente, a quarta seção encerra o artigo com o resumo das principais conclusões, analisadas à luz dos pressupostos de produtividade com inovação tecnológica.

\section{Metodologia e fonte dos dados}

A partir de meados da década de 1960, a adoção de uma política voltada para a modernização do setor rural tornou-se preferível à reforma agrária como solução para o abastecimento alimentar. A divulgação do trabalho de Schultz (1964) - segundo o qual o desenvolvimento somente era alcançado pela transformação da agricultura tradicional, por meio da modernização das técnicas agrícolas e de investimento em capital humano — reforçou o crescimento da produtividade agrícola.

Para Souza (2005), a questão das relações de trocas entre países, envolvendo países produtores de bens primários e produtores de bens industrializados, sempre foi desfavorável aos primeiros. Nesse contexto, Prebisch (1949) afirma que a origem das desigualdades entre os países estava na diferença das estruturas de mercado de produtos e de fatores, originária do maior dinamismo de um particular país. A hipótese da concorrência perfeita aplica-se apenas a situações muito restritas. Nesse sentido, a apropriação desigual do progresso técnico, mediante deterioração dos termos de troca, é resultado da existência de monopólios em alguns mercados e de concorrência em outros. Assim, Prebisch (1949) explica essa deterioração do termo de troca: 
Niraldo José Ponciano, Paulo Marcelo de Souza,

Henrique Tomé da Costa Mata \& Edenio Detmann

...Os preços primários sobem com mais rapidez que os finais na crescente, mas também descem mais que estes na minguante; dessa forma, os preços finais se vão apartando, progressivamente, dos preços primários. I .../ A razão é muito simples. Durante a crescente, uma parte dos benefícios se foi transformando em aumento de salários, pela concorrência dos empresários uns com os outros e pela pressão sôbre todos êles das organizações operárias. Quando, na minguante, o benefício tem que comprimir-se, aquela parte que se transformou em ditos aumentos perdeu, no centro, sua fluidez, em virtude da conhecida resistência à baixa dos salários. A pressão se desloca então para a periferia com maior fôrça que a naturalmente exercível caso não fossem rígidos os salários e os benefícios no centro, em virtude da limitação da concorrência. Assim, tanto menos possam comprimir-se as remunerações, no centro, tanto mais terão que fazê-lo na periferia. /.../ Nisto está a chave do fenômeno pelo qual os grandes centros industriais não apenas retêm para si o fruto da aplicação das inovações técnicas à sua própria economia, mas, ainda, estão em posição favorável para captar uma parte do que surge no progresso técnico da periferia. [Prebisch (1949; pp. 58 e 59)]

O ganho de produtividade na produção dos produtos industrializados será repartido entre os empresários e os trabalhadores dos países centrais, uma vez que a falta de concorrência no mercado de produto não fará com que o ganho de produtividade seja repassado, via redução de preço, para os consumidores. No entanto, o ganho de produtividade na produção dos produtos primários será apropriado integralmente pelos consumidores nos países centrais. A elevada concorrência no mercado de produto fará com que o ganho de produtividade, mediante a queda nos preços, seja transferido para os consumidores. 
Da mesma forma que Prebisch em 1949 interpreta que a questão do desenvolvimento desigual é vista como resultado de assimetrias nas condições de mercado de fatores e de produtos, este trabalho também se propõe a analisar o comportamento da rentabilidade da produção agrícola por meio da relação dos termos de troca. No mercado agrícola brasileiro pressupõe-se que há apropriação desigual do progresso técnico gerando deterioração dos termos de troca para o agricultor, uma vez que parte desses efeitos pode ser atribuída à existência de mercados concentrados a montante e a jusante da produção agrícola.

Os três insumos mais importantes nos custos de produção de grãos são fertilizantes, máquinas e combustíveis. Nas planilhas de custos da Embrapa e nos sistemas de produção de soja analisados por Godinho et al. (1997), foi possível estimar que se gasta cerca de $32 \%$ com fertilizantes, $12 \%$ com máquinas e $8 \%$ com combustíveis. Tomando médias de alguns anos, de diferentes sistemas de produções de arroz e de comparações entre sistemas de plantios direto e convencional para milho, conforme Melo Filho e Mendes (1999), foi possível estimar médias semelhantes para as culturas de milho e de arroz girando em torno de $30 \%, 11 \%$ e $7 \%$ os gastos com fertilizantes, máquinas e combustíveis, respectivamente.

Utilizou-se análise de séries temporais para avaliar as mudanças ocorridas no setor agrícola no período de 1975 a 2005. Por esse método é analisado o comportamento passado de uma variável, visando fazer projeções sobre o seu comportamento futuro. Entre os muitos métodos de análise de séries temporais, tem-se a Taxa Geométrica de Crescimento (TGC).

A TGC é um método que tem sido muito usado em análises econômicas, por ser simples e eficiente de projeção, sendo encontrado como opção em vários softwares estatísticos. Essa metodologia de cálculo parte do pressuposto de que as tendências passadas persistirão no futuro, sendo calculada da seguinte forma:

$$
\log (Y t)=\beta 1+\beta 2 \mathrm{t} \quad \mathrm{TGC}=\left(\mathrm{e}^{\mathrm{bt}}-1\right) 100
$$


Niraldo José Ponciano, Paulo Marcelo de Souza,

Henrique Tomé da Costa Mata \& Edenio Detmann

em que: $Y t$ : variável Y no tempo $t ; \quad \beta t$ : coeficientes a serem estimados; e t: número de períodos (anos) entre a observação final e a inicial.

Adicionalmente, calculou-se o termo de troca por meio do índice de acompanhamento da relação entre o preço de oferta dos insumos e o preço obtido pelo agricultor. Obteve-se esse índice dividindo o preço do insumo pelo preço do produto agrícola. Assim, o quociente dessa divisão indica a quantidade de grãos necessária para adquirir uma unidade comercial do insumo. Se ocorrer crescimento dos preços dos insumos ou decréscimo dos preços dos produtos agrícolas, os termos de troca tendem a se deteriorar para o produtor. Além da variação relativa de preços, a modernização da produção agrícola e sua conseqüente expansão da produtividade podem desencadear efeito contrário ou compensador nos termos de troca, amenizando a situação anterior.

Em termos de fonte de dados, para determinação da relação de troca foram utilizadas séries históricas dos índices de preços médios dos produtos (arroz, milho, café e soja) e dos insumos (combustível, fertilizantes e máquinas agrícolas). Esses dados foram obtidos do site: http:// www.ipeadata.gov.br/ipeaweb.dll/ipeadata. Todos os preços foram corrigidos pelo Índice Geral de Preços (IGP-DI), da revista Conjuntura Econômica da Fundação Getúlio Vargas, tomando como base dezembro de 2005 .

Os dados referentes a área e produção de cada cultura utilizados no cálculo da taxa geométrica de crescimento foram obtidos do mesmo site (http://www.ipeadata.gov.br/ipeaweb.dll/ipeadata), tendo sido oriundos do Instituto Brasileiro de Geografia e Estatística - Pesquisa Agrícola Municipal (IBGE/PAM). 


\section{Resultados e discussão}

A maior parte da expansão da produção de grãos resultou tanto do crescimento da utilização de insumos modernos (fertilizantes, defensivos, sementes melhoradas e mecanização), como do aumento da produtividade desses fatores. Por meio da metodologia de Tornqvist, Gasques et al. (2004) estimaram os índices de produtividade total dos fatores para a agricultura brasileira no período de 1975 a 2002, tendo constatado que a produtividade total dos fatores cresceu a uma taxa média anual de $3,30 \%$, enquanto nos Estados Unidos esse crescimento tem sido de $1,57 \%$ ao ano. Em se tratando de produtividades parciais da agricultura, encontraram-se crescimentos anuais de 3,82\% para produtividade da terra, de 3,27\% para produtividade da mão-de-obra e de 2,69\% para produtividade do capital.

Observa-se, no Quadro 1, que a cultura da soja apresenta a maior taxa geométrica de crescimento anual (5,27\%), seguida do milho (3,47\%); já arroz e café mostram crescimento moderado na produção. Além da produção, a soja expandiu tanto em área plantada quanto em produtividade. Houve forte redução da área cultivada com arroz, o que pode ter ocorrido em função da redução de plantios extensivos de sequeiro, cuja finalidade era cultivar terras recém-desmatadas para plantios de outras culturas e de pastagens. Mesmo com forte redução de área, a produção de arroz apresentou-se crescente graças à expansão da produtividade $(3,41 \%)$ ao ano, com destaque para o plantio de arroz irrigado na região Sul. Apesar de a área plantada com milho praticamente permanecer estagnada, sua produção cresceu devido ao comportamento favorável da produtividade. 
Niraldo José Ponciano, Paulo Marcelo de Souza,

Henrique Tomé da Costa Mata \& Edenio Detmann

Quadro 1 - Taxa Geométrica de Crescimento (TGC) no período de 1975 a 2005 - Brasil

\begin{tabular}{|c|c|c|c|}
\hline ATIVIDADES & PRODUÇÃO & ÁREA & PRODUTIVIDADE \\
\hline TGC ARROZ & $0,739 \%$ aа $* *$ & $-2,580 \%$ aа* & $3,407 \%$ aa* \\
\hline TGC MILHO & $3,472 \%$ aa* & $0,017 \% \mathrm{aa}^{\mathrm{ns}}$ & $3,454 \%$ aa* \\
\hline TGC CAFÉ & $0,886 \%$ aa $^{n s}$ & $0,286 \%$ aa $^{\text {ns }}$ & $0,599 \% \mathrm{aa}^{\mathrm{ns}}$ \\
\hline TGC SOJA & $5,268 \%$ aа* & $2,887 \%$ aа* & $2,314 \%$ aа* \\
\hline
\end{tabular}

* significativo a $1 \%$; ** significativo a $5 \%$; ns: não-significativo.

Fonte: Cálculo da pesquisa.

Verifica-se crescimento da produtividade de arroz $(3,41 \%)$, de milho $(3,45 \%)$ e de soja $(2,31 \%)$ no período analisado. Pode-se dizer que a melhoria da performance dos grãos deveu-se ao desenvolvimento de novas variedades, do plantio mecanizado, do plantio irrigado para algumas culturas, da correção e adubação e da exploração eficiente da região dos cerrados.

A finalidade da análise dos termos de troca é desenvolver, especificamente para cada cultura, sua relação com os insumos modernos e o papel da produtividade na renda do produtor agrícola. As figuras 3, 4 e 5 apresentam as relações de troca entre arroz e seus principais insumos sem considerar a produtividade e considerando o efeito produtividade. Ao se observar uma série de valores (relação de troca) nos gráficos, é importante mencionar que, quanto maior o valor apresentado, menor o poder de compra do agricultor ao longo do tempo. Assim, essa relação nada mais é do que a quantidade de produto agrícola que o produtor precisa vender para adquirir uma quantidade de insumo. 


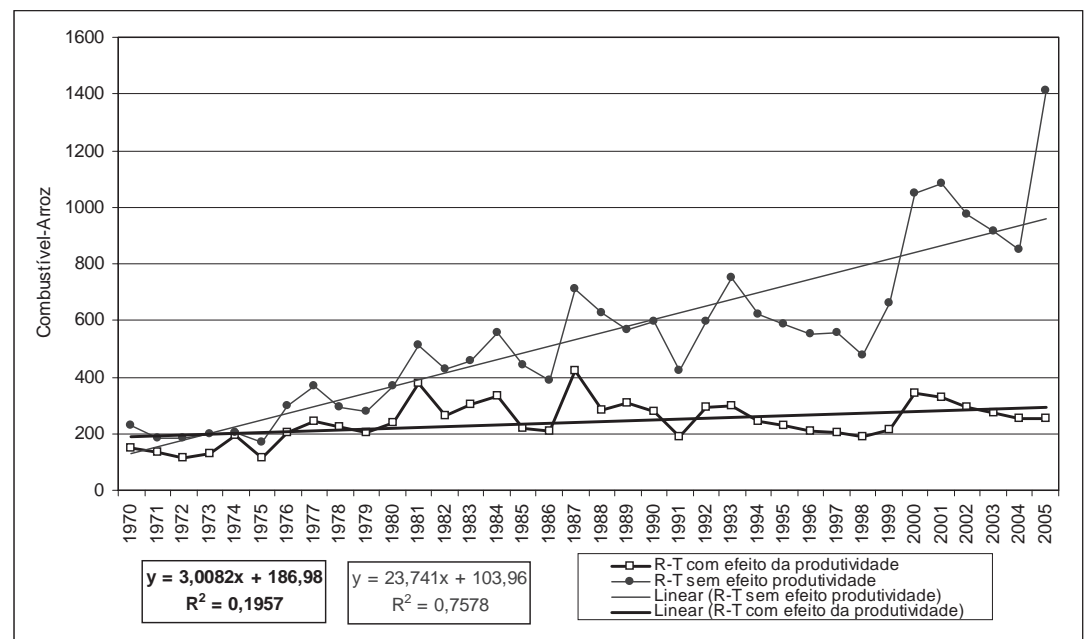

Figura 3 - Relação de troca ou quantidade $(\mathrm{kg})$ de arroz necessária para adquirir mil litros de combustível, no período de 1970 a 2005.

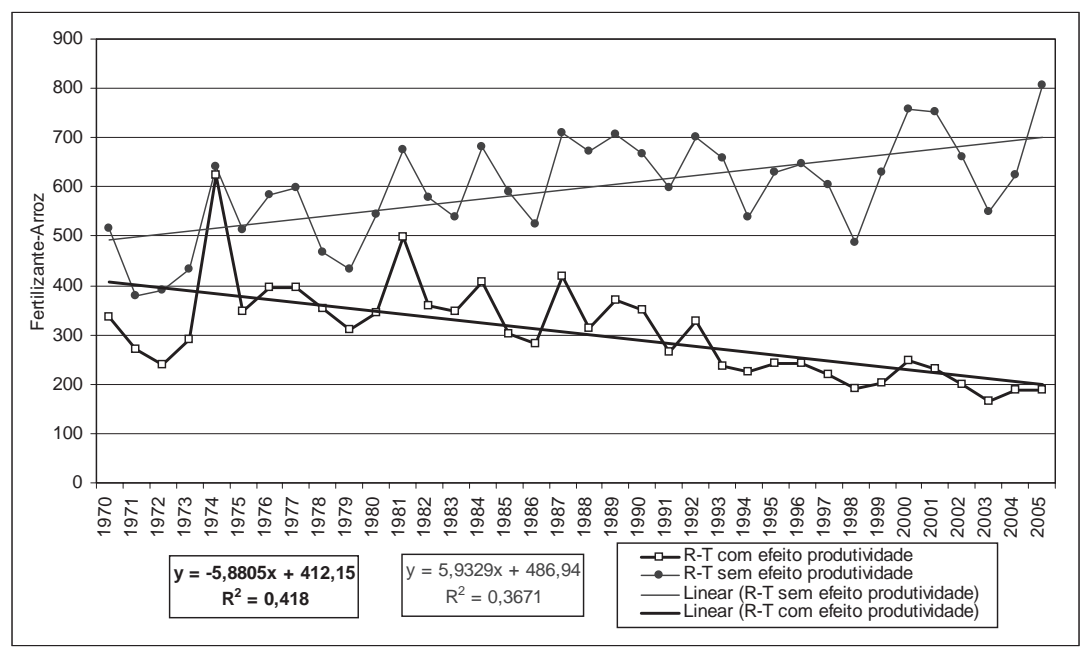

Figura 4 - Relação de troca ou quantidade $(\mathrm{kg})$ de arroz necessária para adquirir uma tonelada de fertilizante, no período de 1970 a 2005 . 
Observa-se que, sem considerar o efeito da produtividade, ocorreu forte tendência de deterioração dos termos de troca entre arroz e seus principais insumos. Em 1970, gastavam-se em torno de $200 \mathrm{~kg}$ de arroz para comprar mil litros de combustível; em 2005, esse gasto foi de mais de $1.000 \mathrm{~kg}$ de arroz. Gastavam-se $500 \mathrm{~kg}$ de arroz para adquirir uma tonelada de fertilizante, e em 2005 passou a se gastar mais de $700 \mathrm{~kg}$ de arroz. Era necessário $300 \mathrm{~kg}$ de arroz para adquirir uma máquina agrícola; em 2005, gastavam-se mais de $600 \mathrm{~kg}$ de arroz para comprar a mesma máquina.

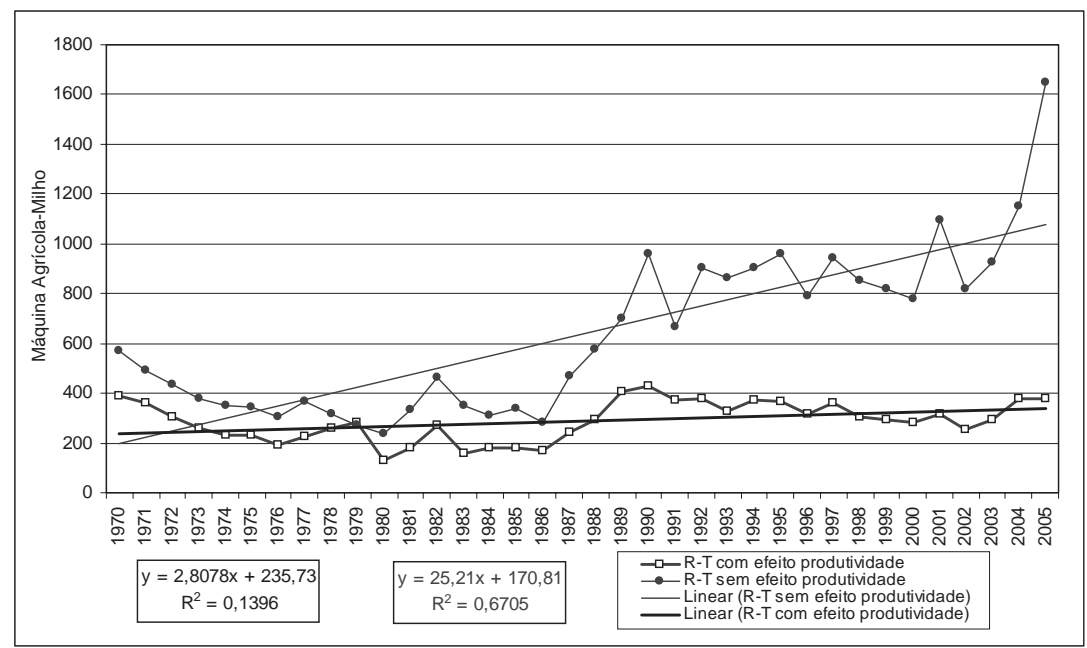

Figura 5 - Relação de troca ou quantidade $(\mathrm{kg})$ de arroz necessária para adquirir uma máquina agrícola, no período de 1970 a 2005.

Verifica-se que o crescimento da produtividade do arroz foi bastante significativo. Considerando o efeito da produtividade, nota-se forte compensação na relação de troca com todos os insumos, inclusive para fertilizante; tem-se gastado menos arroz para adquirir a mesma tonelada de fertilizante. A cultura do arroz sequeiro foi pioneira no processo de ocupação das fronteiras agrícolas brasileiras, precedendo a pecuária bovina na formação de pastagens e também outras culturas. Embora esse tipo de produção seja marginal, apresenta baixa produtividade e 
possui importância relativa reduzida. Por sua vez, o arroz irrigado apresenta-se produtivo e seu plantio concentra-se no sul do País.

As figuras 6, 7 e 8 mostram as relações de troca entre milho e seus principais insumos. Verifica-se que houve tendência de deterioração dos termos de troca em dois dos principais insumos (combustível e máquinas) utilizados nos plantios comerciais de milho. Em 1970, gastavam-se menos de $500 \mathrm{~kg}$ de milho para comprar mil litros de combustível; em 2005, era necessário mais de $2.000 \mathrm{~kg}$ de milho para comprar a mesma quantidade de combustível. Em 1970, gastavam-se em torno de $550 \mathrm{~kg}$ de milho para adquirir uma máquina agrícola, e em 2005 gastava-se mais do dobro $(1.400 \mathrm{~kg})$ de milho.

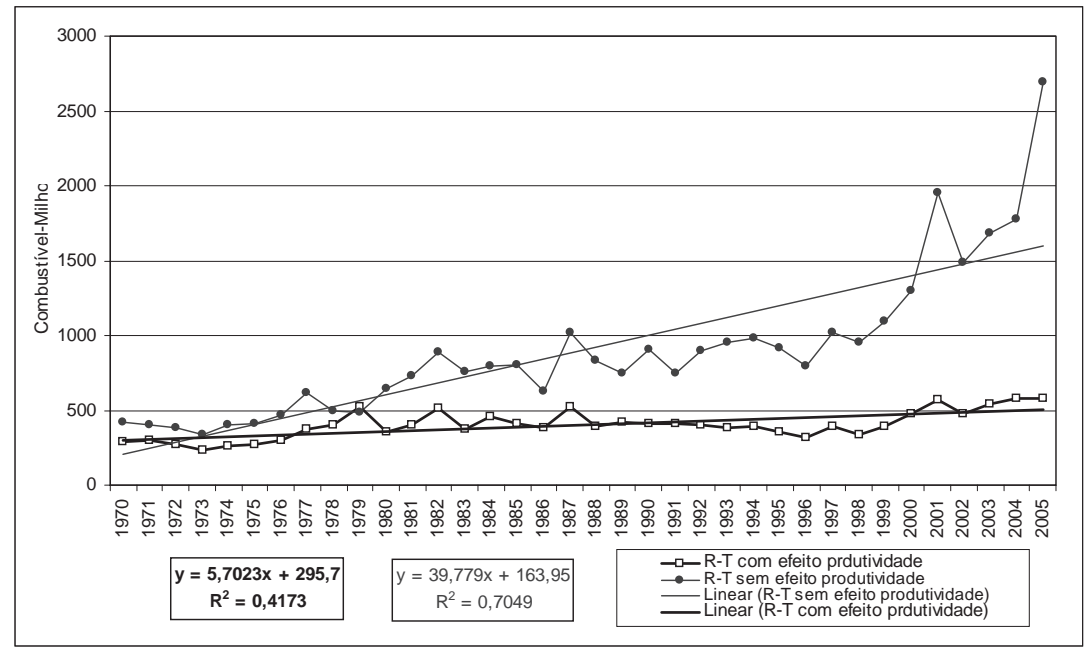

Figura 6 - Relação de troca ou quantidade $(\mathrm{kg})$ de milho necessária para adquirir mil litros de combustível, no período de 1970 a 2005. 
Niraldo José Ponciano, Paulo Marcelo de Souza,

Henrique Tomé da Costa Mata \& Edenio Detmann

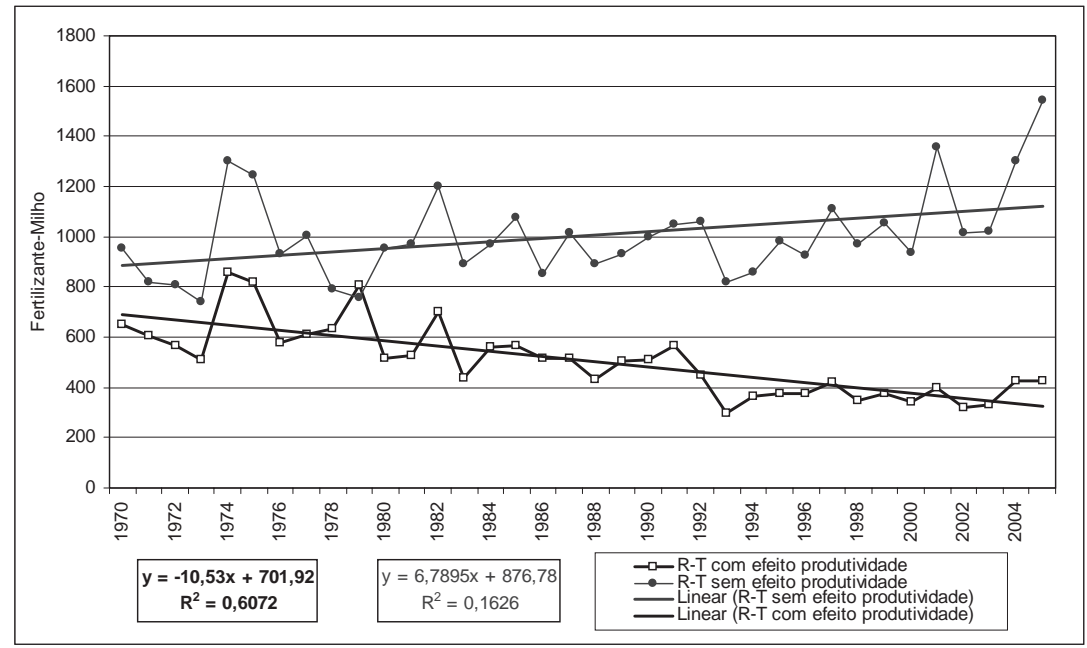

Figura 7 - Relação de troca ou quantidade $(\mathrm{kg})$ de milho necessária para adquirir uma tonelada de fertilizante, no período de 1970 a 2005.

O crescimento da produtividade do milho foi bastante significativo. Considerando o efeito da produtividade, nota-se elevado efeito compensatório na relação de troca com todos os insumos. No caso de fertilizante, conseguiu-se inverter a tendência e até mesmo tornar uma relação bastante favorável para o produtor de milho; assim, em 2005 gastou-se menos milho para adquirir uma tonelada de fertilizante do que há 36 anos. É importante dizer que houve queda nos preços de fertilizante no período em análise. 


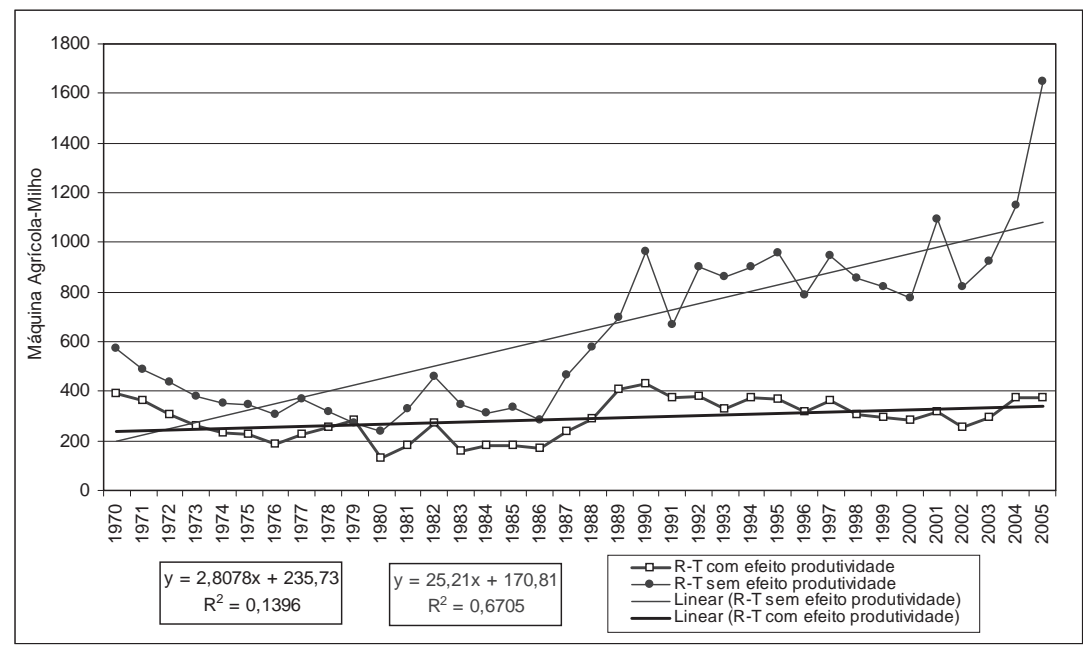

Figura 8 - Relação de troca ou quantidade $(\mathrm{kg})$ de milho necessária para adquirir uma máquina agrícola, no período de 1970 a 2005 .

De acordo com Ponciano et al. (2003), a crise de crédito rural do início da década de 1980 afetou a produção de milho. Nos últimos anos surgiram novas formas de financiamento, como o Programa de Fortalecimento da Agricultura Familiar (Pronaf), no final dos anos 90. Têm sido desenvolvidos novos instrumentos para financiamento, comercialização e proteção de preços, dentre os quais se destacam as Cédulas de Produto Rural CPR, os Mercados de Futuros na BM\&F, os contratos de opções de vendas lançados pelo governo e os Prêmios de Escoamento da Produção - PEPs. Esses instrumentos têm dinamizado a produção de milho.

As figuras 9, 10 e 11 apresentam as relações de troca entre café e seus principais insumos. Observa-se elevada deterioração dos termos de troca entre café e seus principais insumos. Em 1970, gastavam-se em torno de $80 \mathrm{~kg}$ de café para comprar mil litros de combustível; em 2005, era necessário quase cinco vezes mais $(300 \mathrm{~kg}$ ) para comprar a mesma quantidade de combustível. Gastavam-se $170 \mathrm{~kg}$ de café para adquirir 
Niraldo José Ponciano, Paulo Marcelo de Souza,

Henrique Tomé da Costa Mata \& Edenio Detmann

uma tonelada de fertilizante, e em 2005 esse gasto era de $191 \mathrm{~kg}$ de café para comprar a mesma quantidade. Gastavam-se $100 \mathrm{~kg}$ de café para adquirir uma máquina agrícola; em 2005, precisava-se de mais de $200 \mathrm{~kg}$ de café para comprar a mesma máquina.

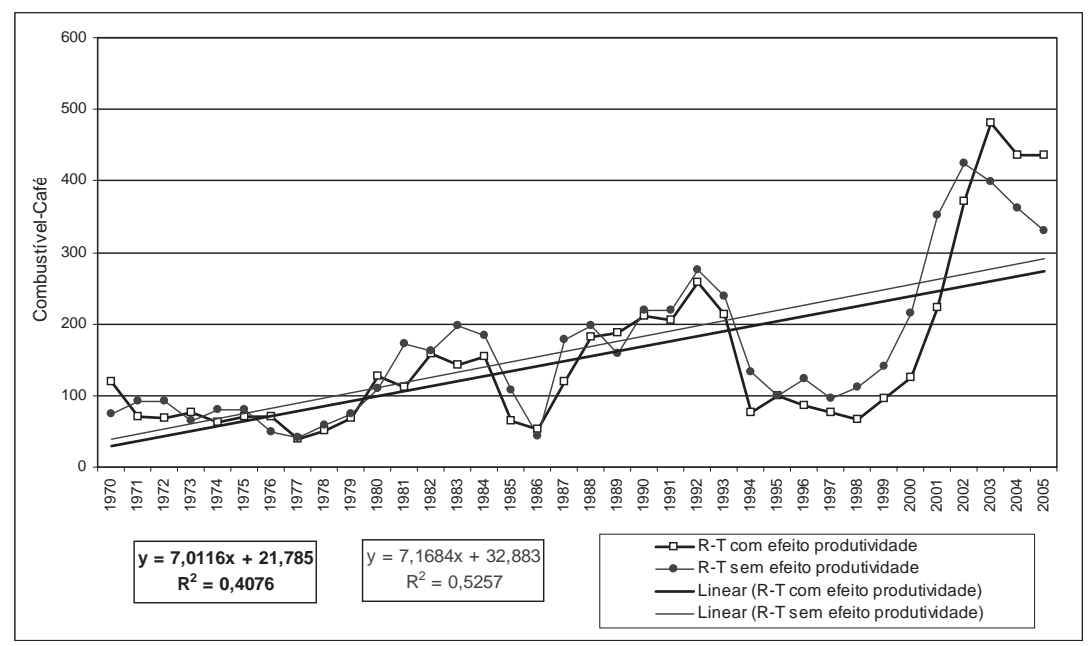

Figura 9 - Relação de troca ou quantidade (kg) de café necessária para adquirir mil litros de combustível, no período de 1970 a 2005. 


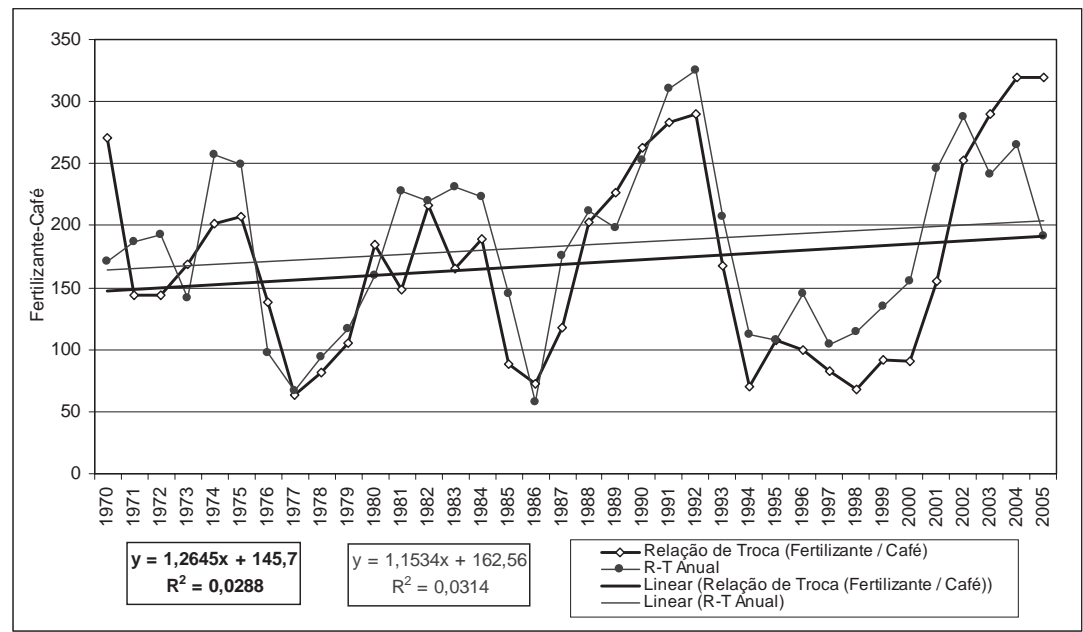

Figura 10 - Relação de troca ou quantidade $(\mathrm{kg})$ de café necessária para adquirir uma tonelada de fertilizante, no período de 1970 a 2005.

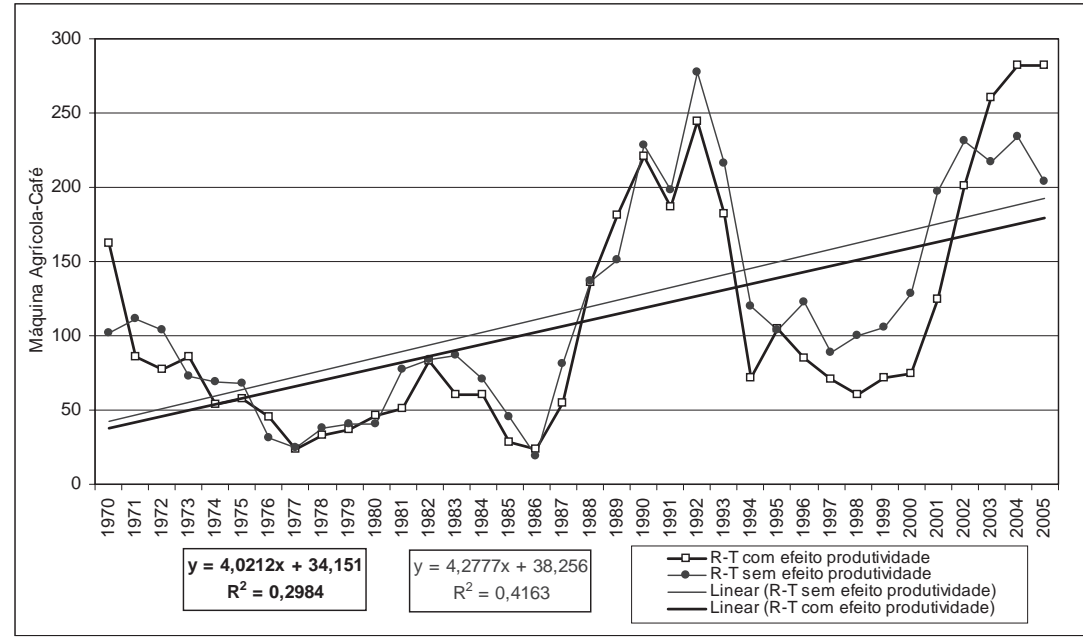

Figura 11 - Relação de troca ou quantidade (kg) de café necessária para adquirir uma máquina agrícola, no período de 1970 a 2005. 
Niraldo José Ponciano, Paulo Marcelo de Souza,

Henrique Tomé da Costa Mata \& Edenio Detmann

Observa-se que o crescimento da produtividade do café foi modesto. Considerando o efeito da produtividade, nota-se discreto efeito compensatório na relação de troca. Nesse sentido, fica evidente que as inovações tecnológicas responsáveis pelo crescimento da produtividade tiveram pouca evolução nesse período. Por ser uma cultura perene, as pesquisas de inovações de variedades mais produtivas são mais lentas, $\mathrm{o}$ que faz com que sua modernização seja relativamente mais tímida em relação aos outros grãos.

Uma série de ajustes na política agrícola brasileira e no comércio internacional afetou a produção de café nas últimas décadas. A política cambial foi a que mais afetou o comportamento dos preços do café nesse período. Observa-se que no início da década de 1990 o preço do café encontrava-se reduzido; com a maxidesvalorização do câmbio no final de 1991, inverteu-se a tendência da relação de troca nos anos seguintes. Os produtores têm-se adequado às exigências do mercado, de acirrada competição de preços, de melhoria na qualidade e de ausência de interferências governamentais (Bacha, 1998).

As figuras 12, 13 e 14 ilustram as relações de troca entre soja e seus principais insumos, sem considerar e considerando o efeito produtividade. 


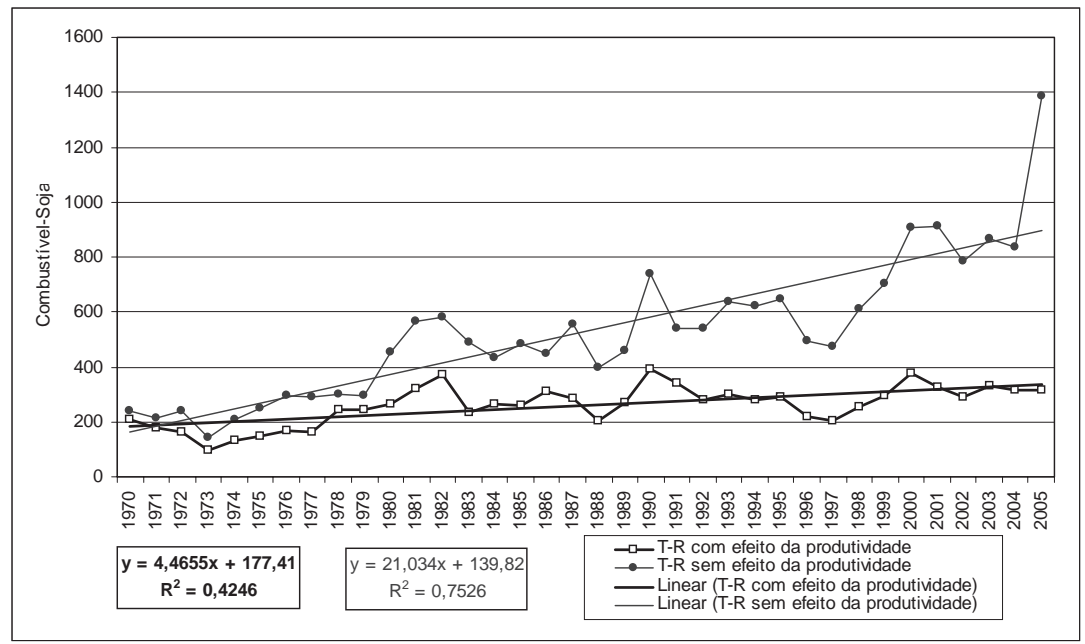

Figura 12 - Relação de troca ou quantidade (kg) de soja necessária para adquirir mil litros de combustível, no período de 1970 a 2005.

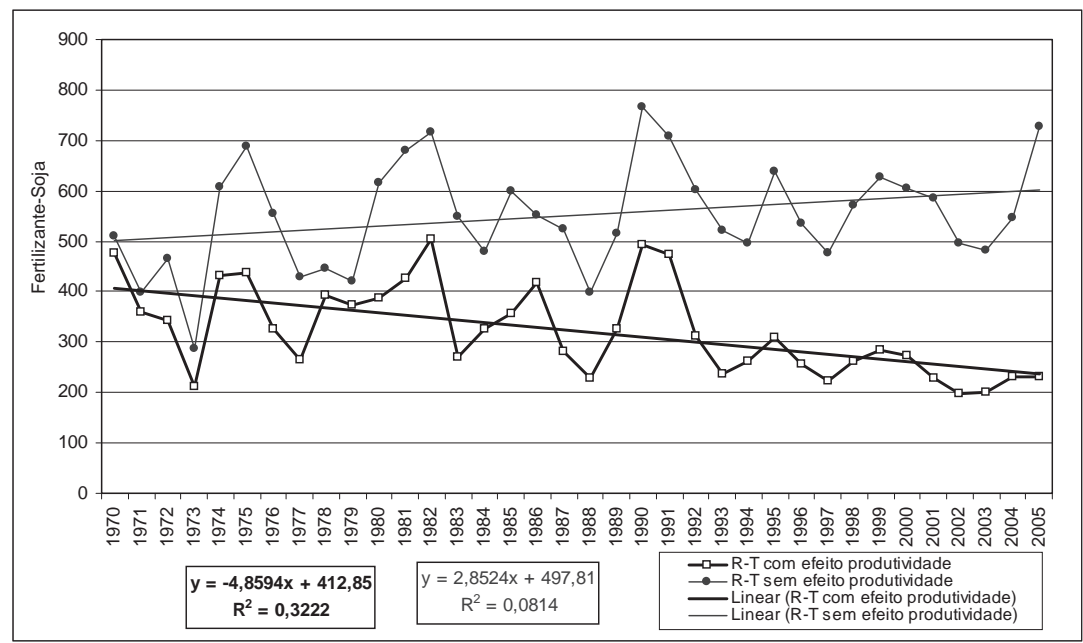

Figura 13 - Relação de troca ou quantidade $(\mathrm{kg})$ de soja necessária para adquirir uma tonelada de fertilizante, no período de 1970 a 2005. 
$\mathrm{Na}$ situação em que não se considera o efeito produtividade, ocorreu forte tendência de deterioração dos termos de troca entre soja e insumos combustível e máquinas. Em 1970, gastavam-se $240 \mathrm{~kg}$ de soja para comprar mil litros de combustível; nos últimos anos, tem se gastado mais de três vezes $(800 \mathrm{~kg})$ de soja para comprar a mesma quantidade de combustível. Gastavam-se em torno de $328 \mathrm{~kg}$ de soja para adquirir uma máquina agrícola; nos últimos anos, esse gasto tem sido de mais de 600 $\mathrm{kg}$ de soja.

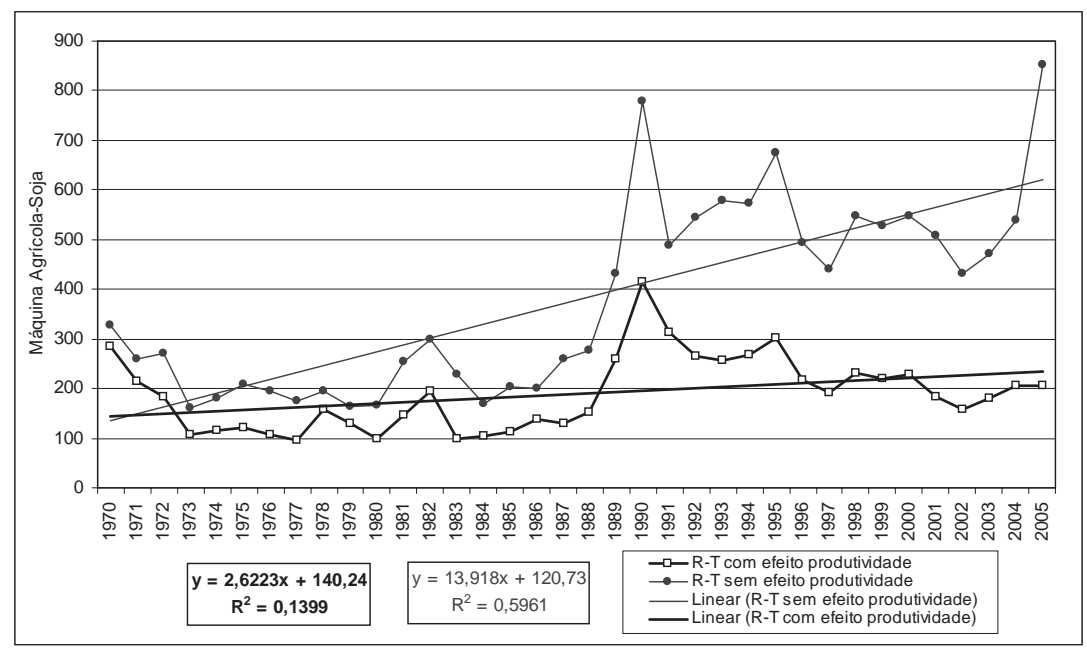

Figura 14 - Relação de troca ou quantidade $(\mathrm{kg})$ de soja necessária para adquirir uma máquina agrícola, no período de 1970 a 2005.

Observa-se elevado crescimento da produtividade da soja. Considerando o efeito da produtividade, nota-se forte efeito compensatório na relação de troca com todos os insumos. Como houve queda nos preços de fertilizante, conseguiu-se inverter a tendência e até mesmo tornar uma relação bastante favorável para o produtor de soja; assim, em 2005 gastase menos soja para adquirir uma tonelada de fertilizante do que em 1970.

A expansão da produção de soja no Brasil, a partir da década de 1970, não foi conseqüência de um único fator. Destacam-se o deslocamento 
geográfico para a região dos cerrados, o aumento da escala de produção e a incorporação de novas tecnologias (plantio direto e sementes oriundas de biotecnologia). Em termos gerais, favoreceram as boas oportunidades do mercado externo e a integração com a agroindústria processadora. Apesar de o Brasil apresentar elevada eficiência na produção de soja, com baixos custos e elevada produtividade, a atividade convive com problemas de infra-estrutura de transporte.

\section{Conclusão}

No período de 1970 a 2005, ocorreu forte tendência de deterioração dos termos de troca para os produtores de arroz, de milho, de soja e de café. Os termos de trocas beneficiaram o setor a montante da agricultura, principalmente os vendedores de combustíveis e de máquinas agrícolas. Esse comportamento dos termos de troca agrícola pode ser interpretado pela baixa elasticidade-preço da oferta.

Constatou-se que os efeitos dos preços pagos sobre os preços recebidos foram mais acentuados para arroz e milho. Esse comportamento associase ao fato de as culturas de arroz e de milho serem destinadas ao mercado interno e de suas demandas serem mais inelásticas em relação às culturas de soja e de café. Além disso, as alterações dos preços pagos pelos insumos deslocaram mais as ofertas de arroz e de milho.

Antes da estabilização da economia em 1994, a deterioração nos termos de troca para o agricultor pode ser explicada pela baixa elasticidadepreço da oferta, combinada com a queda da elasticidade-renda da demanda pelas mercadorias agrícolas, em relação aos insumos industrializados. A partir do Plano Real, que coincide com a abertura econômica, observou-se maior estabilidade nos preços dos produtos e na relação de troca, porém não se verificou tendência favorável para o produtor rural. 
Niraldo José Ponciano, Paulo Marcelo de Souza,

Henrique Tomé da Costa Mata \& Edenio Detmann

Conclui-se que as inovações tecnológicas indutoras da expansão da produtividade de grãos desempenharam papel importante no período analisado, mas foram insuficientes para compensar o viés do efeito desfavorável, no qual os preços dos grãos reduziram em magnitudes significativas em relação ao comportamento dos preços pagos pelos produtores por insumos combustíveis, fertilizantes e máquinas. Assim, a relação de troca foi desfavorável para os produtores desses grãos, uma vez que o efeito preço relativo sobrepôs-se ao efeito compensação da produtividade. Dessa forma, houve modernização na produção de grãos, porém com redução da renda do produtor agrícola.

\section{Referências}

BACHA, C.J.C. A cafeicultura brasileira nas décadas de 80 e 90 e suas perspectivas. Preços Agrícolas, Piracicaba, v.7, n.142, p.14-22, 1998.

DELFIM NETTO, A. O problema do café no Brasil. São Paulo: IPE/ USP, 1981.

GASQUES, J.G.; BASTOS, E.T.; BACCHI, M.P.R.; CONCEIÇÃO, J.C.P.R. Condicionantes da produtividade da agropecuária brasileira. Revista de Política Agrícola, Brasília, v. XIII, n. 3, jul./ago. 2004.

GODINHO, V. P.C.; PRADO, E.E. do; UTUMI, M.M.; OLIVEIRA, S.J.M. Estimativa de custos de produção de soja, em plantio convencional, para a região do cerrado de Rondônia, safra 1997/ 98. Porto Velho: EMBRAPA - CPAF Rondônia, 1997. 4p. (EMBRAPACPAF, Rondônia. Comunicado Técnico, 137).

HOFFMAN, R. A diminuição do consumo de feijão no Brasil. Anais do XXXII Congresso Brasileiro de Economia e Sociologia Rural, Brasília, v. II, 1994. 
IPEA - Instituto de Pesquisa Econômica Aplicada. Pesquisa de Preços http://www.ipeadata.gov.br em 23-02-2006 página mantida pelo Instituto de Pesquisa Econômica Aplicada.

KAM-CHINGS, M. H. F. L.; TEIXEIRA, E. C. Política de garantia de renda e equivalência em produto: análise comparativa de custos e benefícios. Revista de Economia e Sociologia Rural, Brasília, v. 33, n. 1, 1995.

MELO FILHO G. A. de; MENDES D. S. Estimativa de custo de produção de milho nos sistemas plantio direto e convencional. Comun. Téc. Embrapa Agropec. Oeste, n.3, ago./1999.

NAKANO, Y. A destruição da renda da terra e da taxa de lucro na agricultura. Revista de Economia Política, São Paulo, v. 1, n. 3, p. 315 , jul/set-1981.

PONCIANO, N.J.; SOUZA, P.M.; REZENDE, A.M. Entraves da comercialização à competitividade do milho brasileiro. Revista Paranaense de Desenvolvimento, Curitiba, n. 104, p. 23-40, jan./ jun.2003.

PREBISCH, R. O desenvolvimento da América Latina e seus principais problemas. Revista Brasileira de Economia, Rio de Janeiro, v. 3, n. 3, setembro de 1949.

SCHULTZ, T. W. Transforming traditional agriculture. New Haven and London: Yale University Press, 1964.

SOUZA, N. J. Desenvolvimento econômico. 5. ed. São Paulo: Atlas, 2005. 
Niraldo José Ponciano, Paulo Marcelo de Souza,

Henrique Tomé da Costa Mata \& Edenio Detmann

\begin{abstract}
The objective of this work was to evaluate, by means of the exchange rate, the profitability of two products directed toward the domestic market and two export products. Other objective was to identify productivity growth compensated the decrease of prices. The geometric rates of the production, area and productivity growth were estimated. The exchange rate was estimated by the relation between the index of the inputs prices and the index of the product prices. The results show a great trend of deterioration of the exchange terms for all the analyzed products. Evidenced that these effects more was been accented for rice and maize. Such behavior associates it the fact of the rice cultures and of maize to be destined to the domestic market, its demands have been not elastic in relation to the coffee and soy cultures.
\end{abstract}

Keywords: terms of exchange, grains, inputs, prices, productivity, income. 
REVISTA DE ECONOMIA E AGRONEGÓCIO, VOL.5, $N^{\circ} 2$ 